\title{
Characterization of mitochondrial iron uptake in HepG2 cells
}

\author{
DORA INÉS MAZARIEGOS ${ }^{1}$, Z. IOAV CABANTCHIK ${ }^{2}$, BRUCE K. CASSELS $^{3}$ \\ and MARCO TULIO NÚÑNEZ ${ }^{4}$
}

\footnotetext{
${ }^{1} \mathrm{PhD}$ Program in Cell, Molecular and Neural Biology, Faculty of Sciences, Universidad de Chile;

${ }^{2}$ Life Sciences Program, Alexander Silberman Institute of Life Sciences, Hebrew University of Jerusalem;

${ }^{3}$ Chemistry Department and Cell Dynamics and Biotechnology Research Center, Faculty of Sciences, Universidad de Chile and

${ }^{4}$ Biology Department and Cell Dynamics and Biotechnology Research Center, Faculty of Sciences, Universidad de Chile
}

\begin{abstract}
There is increasing evidence that accumulation of redox-active iron in mitochondria leads to oxidative damage and contributes to various neurodegenerative diseases, such as Friedreich's ataxia and Parkinson's disease. In this work, we examined the existence of regulatory mechanisms for mitochondrial iron uptake and storage. To that end, we used rhodamine B-[(1,10-phenanthrolin-5-yl)amino carbonyl] benzyl ester, a new fluorescent iron-sensitive probe that is targeted specifically to the mitochondrion. We found that extracellular iron was incorporated readily into mitochondria in an apparently saturable process. Moreover, the rate of iron incorporation responded to the Fe status of the cell, an indication that the mitochondrion actively regulates its iron content.
\end{abstract}

Key terms: mitochondria, iron homeostasis, RPA, HepG2 cells

\section{INTRODUCTION}

The mitochondrion is the main generator of endogenous reactive oxygen species (ROS) and at the same time, it must ensure an appropriate iron supply for the synthesis of heme and $\mathrm{Fe}-\mathrm{S}$ clusters. There is increasing evidence that accumulation of redox-active iron in mitochondria can lead to oxidative damage and contributes to various human diseases, such as Friedreich's ataxia and Parkinson's disease (Zecca et al., 2004). The use of fluorescent probes that chelate $\mathrm{Fe}$ and are targeted to specific organelles allows the determination of compartmentalized pools of labile (reactive) iron, (LIP) (Espósito et al., 2002; Petrat et al., 2002). In this study, we examined the existence of regulatory mechanisms for mitochondrial iron uptake and storage. To that end, we studied the changes in the mitochondrial labile iron pool, mLIP in HepG2 cells and the generation of ROS upon long- and shortterm exposure to iron.

\section{RESULTS AND DISCUSSION}

Cells were loaded with the mitochondrial, iron-responsive probe rhodamine B-[(1,10phenanthrolin-5-yl)amino carbonyl] benzyl ester (RPA) (Petrat et al., 2002), and fluorescence was recorded with a fluorescence microplate reader. After a basal reading, iron, as ferrous ammonium sulfate (FAS), was offered to cells. Fe was rapidly taken up by mitochondria, as demonstrated by RPA quenching (Fig. 1).

Corresponding author: Dora I. Mazariegos, Department of Biology, Faculty of Sciences, Universidad de Chile, Las Palmeras 3425, Nuñoa, Santiago, Chile, Tel.: (56-2) 978-7247, Fax: (56-2) 271-2983, E-mail: dimazari@icaro.dic.uchile.cl 
RPA quenching was apparently saturable at concentrations of FAS above $10 \mu \mathrm{M}$. These results suggest that mitochondria have a relatively fast and saturable iron uptake system.

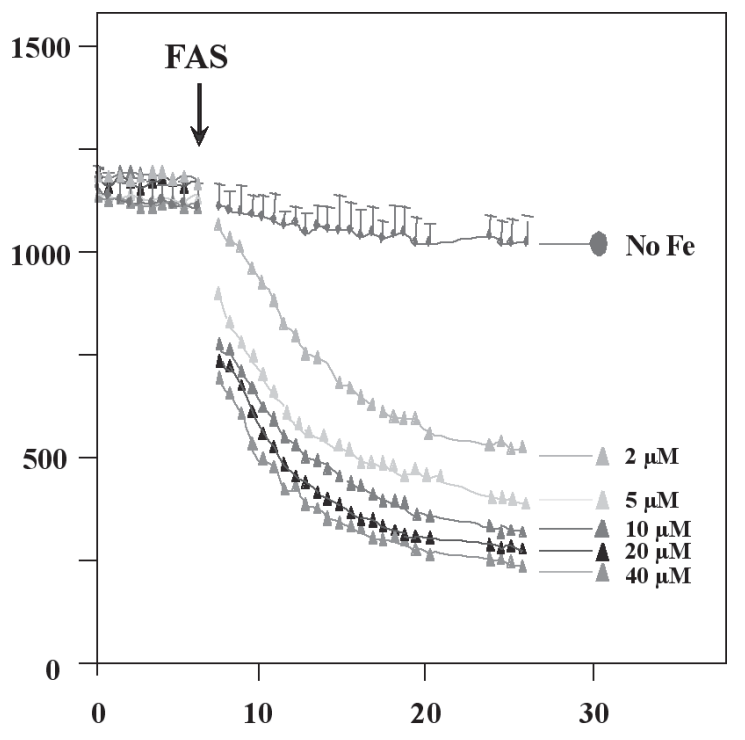

Time, min

Figure 1. Changes in mitochondrial iron in response to changes in extracellular iron. HepG2 cells grown in microplate wells were incubated with RPA and fluorescence was followed in a microplate fluorescence reader after the addition of $0,2,5,10,20$ or $40 \mu \mathrm{M}$ ferrous ammonium sulfate (FAS) to the culture medium. Entry of Fe was fast and apparently saturable.

We determined levels of mitochondrial iron in long-term cultures of HepG2 cells. RPA fluorescence in cells grown for 5 days in iron-deficient medium was stronger than fluorescence in cells grown in control (5 $\mu \mathrm{M} F \mathrm{Fe}$ ) medium, whereas cells cultured in $20 \mu \mathrm{M}$ Fe presented the lowest RPA fluorescence values. No further significant decreases in RPA fluorescence were found in the 20-100 $\mu \mathrm{M}$ Fe range (data not shown). These results suggest that mitochondrial iron levels reflect the iron supply to the cells. We have seen similar relationships between extracellular iron and cytosolic LIP determined by calcein quenching (Núñez et al., 2001).
We then measured the generation of reactive oxygen species (ROS) associated with Fe uptake, by incubating cells previously exposed for $20 \mathrm{~min}$ to 5,10 and $20 \mu \mathrm{M}$ FAS with dihydrodichlorofluorescin diacetate (DHDCF-DA) and recording the appearance of green fluorescence due to oxidation of the probe (Núñez et al., 2001). The rate of ROS production increased by 42,48 and $90 \%$ of the control value with the addition of 5, 10 and $20 \mu \mathrm{M}$ FAS. Similarly, compared to control medium containing $5 \mu \mathrm{M} \mathrm{Fe}$, cells grown for 5 days in $10 \mu \mathrm{M}$ Fe presented increased levels of ROS, whereas no further increases in ROS were found in cells grown in the $10-100 \mu \mathrm{M}$ Fe range. Similarly, no loss in cell viability was found with up to $100 \mu \mathrm{M} \mathrm{Fe}$ in the culture medium. Thus, HepG 2 cells, unlike neuronal cells (Aguirre et al., 2005a, 2005b), have very effective mechanisms to control iron-induced oxidative stress.

In summary, the results presented here show that extracellular iron is readily incorporated into mitochondria, in an apparently saturable process. Moreover, the rate of iron incorporation responds to the $\mathrm{Fe}$ status of the cell, an indication that the mitochondria actively regulate their iron content. Although iron uptake was accompanied by ROS production, HepG2 cells effectively regulated ROS generation. These results suggest that HepG2 cells tightly regulate their mitochondrial iron levels.

\section{ACKNOWLEDGEMENTS}

This work was financed by FONDECYT grant 1040448 and ICM grant P99-031.

\section{REFERENCES}

AGUIRRE P, MENA N, ARREDONDO M, TAPIA V, NÚNẼZ MT (2005a) Iron homeostasis in neuronal cells: a role for SCL40. BMC Neuroscience 6: article 3 AGUIRRE P, MENA $N$, TAPIA V, ROJAS A, ARREDONDO M, NÚÑEZ MT (2005b) Homeostatic and antioxidant responses of neuroblastoma cells to high iron supply. Biol Res, this issue

ESPÓSITO BP, BREUER W, CABANTCHIK ZI (2002) Design and applications of methods for fluorescence detection of iron in biological systems. Biochem Soc Trans 30: 729-732 
NÚNEZ MT, TAPIA V, TOYOKUNI S, OKADA S (2001) Iron-induced oxidative damage in colon carcinoma (Caco-2) cells. Free Radic Res 34: 57-68

PETRAT F, WEISHEIT D, LENSEN M, DE GROOT H, SUSTMANN R, RAUEN U (2002) Selective determination of mitochondrial chelatable iron in viable cells with a new fluorescent sensor. Biochem J 362: $137-147$

ZECCA L, YOUDIM MB, RIEDERER P, CONNOR JR, CRICHTON RR (2004) Iron, brain ageing and neurodegenerative disorders. Nat Rev Neurosci 5: 863873 